\title{
Innovative Technologies for Utilization and Disinfection of Waste to Ensure Sustainable Development of Civilization
}

\author{
Irina Suvorova ${ }^{1}$, Oleg Kravchenko ${ }^{1}$, Igor Baranov ${ }^{1}$, Vitaliy Goman ${ }^{1}$
}

\begin{abstract}
Ensuring sustainable development of civilisation is a major task of modern times. Ecological safety and cleanness of waste utilization and disinfection is one of the global innovation challenges. An essentially new method has been developed for hydrocavitation activation of homogeneous and heterogeneous media. The method enables the production and ecologically safe combustion of new kinds of composite fuels based on off-spec hydrocarbons and different kinds of effluents. This enables solving two problems at the same time - the energy and ecological ones. A methodology is offered for mathematical modelling the fluid dynamics of viscous incompressible fluid flow in intricate passages by using the R-functions method. Its application helped develop new kinds of atomisers for effective mixing, homogenisation, pre-combustion activation and atomisation of highly viscous composite fuels. The tests of the developed devices have confirmed their high effectiveness.
\end{abstract}

Keywords: waste utilization and disinfection, bydrocavitation activation, composite fuels.

\section{Introduction}

Recent years have been witnessing the global contamination of water worldwide. Some open water bodies contain water of such quality that its utilisation without additional purification is impossible even for domestic and production needs. The facts of the globally degrading quality of water is related to local social and economic development, certain water basins, and lakes or underground sources. It is also necessary to account for atmospheric transport of contamination over big distances, thus subjecting clean and remote areas to indirect pollution.

To date, there are but few rivers that have not been subjected to contamination by human activity products. One of the global challenges is the contamination of waste effluents. In the agriculture sector, fertilisers and pesticides make it into rivers with the drainage. In big cities, sewage and waste effluents contribute to contamination. Earlier, the main contamination of surface water and the chernozem soil was the result of discharge of waste effluents. Today, everything is much more complicated because the production of hazardous waste is growing appallingly rapidly and is demonstrating an accumulation trend. There is a growing need in developing and introducing new effective and ecologically safe technologies for decontamination of noxious contaminants of waste effluents. 


\section{Problem Statement}

Scientists are facing a challenge - find ways to ensure sustainable development of civilisation. A major global problem is utilization and disinfection of waste.

The development of an innovative, essentially new technique of hydrocavitation activation of homogeneous and heterogeneous media has opened the prospect of developing technologies for producing composite fuels with specified energy and ecological characteristics.

Proven was the capability of running the process of partial low-temperature (up to $100^{\circ} \mathrm{C}$ ) cracking and hydrocracking of hydrocarbons during their hydrocavitation activation. This enables producing new, high-quality liquid and suspension composite fuels with improved physical-chemical characteristics - artificial composite liquid fuels (ACLF) [1-4].

The research conducted in increasing the effectiveness of atomisation and combustion of such composite fuels has created the prerequisites for producing new quality boiler fuels based on off-spec hydrocarbons, including stale fuel oil, oil tanker outwashes, stillage bottoms, coal, biomass and effluents of different origin (phenolic water, hydrofracing spent liquid, active sludge from waste treatment plants, etc.). This approach helps using raw hydrocarbons more effectively and solving at the same time the energy and ecological problems - generate additional energy, utilization and disinfection of waste.

In order to increase fuel combustion effectiveness and reduce the amount of noxious emissions, both the design of burners and the technologies of liquid fuel combustion need to be improved. The atomisation quality is one of the crucial parameters for managing effective fuel combustion in combustion chambers. This parameter is linked not only to the design features of combustion chambers but also to the energy and ecological indicators of combustion processes. Solving this problem calls for continuous improvement of the design of burners and technologies for liquid fuel combustion. As a rule, to feed fuel to combustion chambers, centrifugal, jet, pneumatic, combined and other types of atomisers are used whose feature is strict requirements to fuel purity. Using suspension-combined fuels prohibits the use in combustion devices of the abovementioned types of atomisers because the presence of the dispersion $k$-phase in the fuel rapidly clogs pipelines and gauged nominal bores. Hence, their use for atomising ACLF is forbidden. Owing to this, hydrovortex atomisers warrant special interest [5-9]. They offer new opportunities for ensuring atomisation quality for hard-to-atomise liquids. The principle of hydrocavitation activation serves as the basis for intensifying the processes of ACLF dispersion and atomisation. When designing new types of atomisers, the main objective is to ensure cavitation zones in the flow, in which superfine liquid dispersion occurs and a high-quality heterogeneous mixture is produced.

Modelling the physical processes occurring in many machines and apparatuses involves analysis of fluid dynamics fields. In such problems, a significant role is set aside for the shapes of fluid passages, which can have several geometric features. The $R$-functions method (RFM) [10-18] enables accounting for the geometric information about the passages at the analytical level and precisely meeting the boundary conditions (BC).

The result of such research was the development of new kinds of atomisers for effective mixing, homogenising, pre-combustion activation and atomisation of high-viscosity 
composite fuels, which have passed tests in actual operating conditions.

\section{Mathematical Modelling of Fluid Dynamics Processes in Atomisers}

The mathematical theory of R-functions (functions established by Rvachev V.L., Academician NAS of Ukraine) [10] was used to develop the methodology of analysing the flow of a viscous incompressible fluid in intricate passages with definition of cavitation zones wherein physical-chemical and heat transfer processes are intensified [15]. Mathematical modelling and computer simulation was used to develop and create unique hydrovortex atomisers. They provide quality ultrafine atomisation of highviscosity composite fuels to ensure enhanced mixing of fuel droplets with the oxidiser. Such atomisers for combustion of composite fuels allow for a dramatic improvement of the performance and ecological indicators of operation of power installations.

\subsection{Problem Statement for the Velocity Field}

A plane steady-state flow of viscous incompressible fluid is described by the following system of differential equations:

$$
\begin{aligned}
& V_{x} \frac{\partial V_{x}}{\partial x}+V_{y} \frac{\partial V_{x}}{\partial y}+E u \frac{\partial P}{\partial x}-\frac{1}{\operatorname{Re}} \Delta V_{x}=0 \\
& V_{x} \frac{\partial V_{y}}{\partial x}+V_{y} \frac{\partial V_{y}}{\partial y}+E u \frac{\partial P}{\partial y}-\frac{1}{\operatorname{Re}} \Delta V_{y}=0 \\
& \frac{\partial V_{x}}{\partial x}+\frac{\partial V_{y}}{\partial y}=0 .
\end{aligned}
$$

Here, (1) and (2) are Navier-Stokes equations, (3) is motion continuity equation, Re is Reynolds number, and $E \boldsymbol{u}$ is Euler number.

By introducing stream function $\psi$ with the help of relationships $V_{x}=\frac{\partial \psi}{\partial y}, V_{y}=-\frac{\partial \psi}{\partial x}$, system (1)-(3) is reduced to a nonlinear differential equation of $4^{\text {th }}$-order partial derivatives for stream function $\psi[19]$

$$
\frac{1}{\operatorname{Re}} \Delta \Delta \psi-\frac{\partial \psi}{\partial y} \cdot \frac{\partial \Delta \psi}{\partial x}+\frac{\partial \psi}{\partial x} \cdot \frac{\partial \Delta \psi}{\partial y}=0
$$

The boundary conditions for such an equation follow from the condition of adhesion on a solid wall and inlet velocity.

\subsection{Boundary Conditions}

For a solid wall, we have the adhesion condition $\left(V_{x}=\frac{\partial \psi}{\partial y}=0, \quad V_{y}=-\frac{\partial \psi}{\partial x}=0\right)$, Hence, it follows, $\frac{\partial \psi}{\partial \tau}=(\nabla \psi, \vec{\tau})=0 ; \quad \frac{\partial \psi}{\partial n}=(\nabla \psi, \vec{n})=0$. Since $\frac{\partial \psi}{\partial \tau}=0$ on a solid wall, $\psi=$ const on the same wall. A parabolic velocity profile is specified at the inlet. 


\subsection{Analysis of the Fluid Dynamics Characteristic of Fuel Flow in an Atomiser}

Problem statement. It is required to find the distribution of the velocities field of a flow through an atomiser. Solving (4) for the stream function in domain $\Omega$, Fig. 1, described by equation $\omega(x, y) \geq 0$ [10], function $\omega(x, y)$ is shown in Fig. 2 .

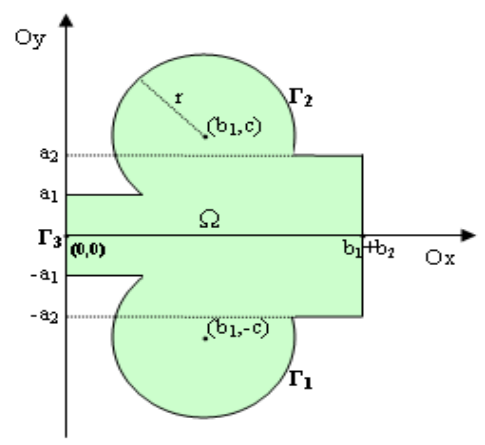

Fig. 1. Domain $\Omega$

Fig. 2. $\omega(x, y)$

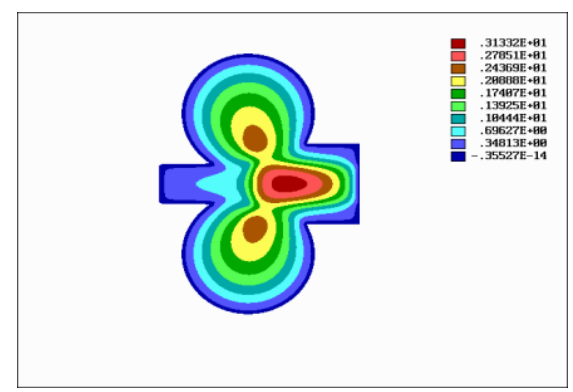

The solution structure for (4) with respective boundary conditions has the form $\psi=\psi_{1}+\psi_{0}$ [11], where $\psi_{0}$ ensures extension of boundary conditions into the domain and the structure is derived using the patching formula [10].

$\psi_{0}=\frac{\sum_{i=1}^{3} \frac{\Psi_{i}}{w_{i}^{2}}}{\sum_{i=1}^{3} \frac{1}{w_{i}^{2}}}$, where $\Psi_{i}$ are values of function $\psi$ specified on sections of boundary $\Gamma_{i}$ described by equation $w_{i}=0$.

For the given problem,

$$
\begin{aligned}
& \Psi_{1}=-\frac{2 a_{1}}{3}, w_{1}=\left(\left(x-b_{1}\right) \wedge_{0}\left(y+a_{2}\right) \vee_{0}\left(y+a_{1}\right) \vee_{0}\left(r^{2}-\left(x-b_{1}\right)^{2}-(y+c)^{2}\right)\right) ; \\
& \Psi_{2}=\frac{2 a_{1}}{3}, w_{2}=\left(\left(x-b_{1}\right) \wedge_{0}\left(a_{2}-y\right) \vee_{0}\left(a_{1}-y\right) \vee_{0}\left(r^{2}-\left(x-b_{1}\right)^{2}-(y-c)^{2}\right)\right) ;
\end{aligned}
$$


$\Psi_{3}=y-\frac{y^{3}}{3 a_{1}^{2}}, w_{3}=x,\left.\psi_{0}\right|_{\Gamma_{i}}=\Psi_{i},\left.\frac{\partial \psi_{0}}{\partial n}\right|_{\Gamma_{i}}=0, i=1,2,3$.

$\psi_{1}$ is unknown function with zero Dirichlet and Neumann boundary conditions, which has the form $\psi_{1}=\omega_{1}^{2} P_{1} . P_{1}=\sum_{i=1}^{N} A_{i} \zeta_{i}$ is an indefinite component of the structure;

$A_{i}$ are constants to be found; $\zeta_{i}$ are special functions forming a basis in Hilbert space, in which the solution is being found.

Following from [10], $\omega_{1}=\left(f_{1} \wedge_{0} f_{2}\right) \vee_{0}\left(f_{3} \wedge_{0} f_{4}\right) \vee_{0}\left(f_{5} \vee_{0} f_{6}\right)$;

$\wedge_{0}(x, y)=x+y-\sqrt{x^{2}+y^{2}}$ is $\mathrm{R}$-conjunction; $\vee_{0}(x, y)=x+y+\sqrt{x^{2}+y^{2}}$ is $\mathrm{R}$ disjunction;

$$
\begin{aligned}
& f_{1}=x\left(b_{1}+b_{2}-x\right) /\left(b_{1}+b_{2}\right) ; f_{2}=\left(a_{1}+y\right)\left(a_{1}-y\right) /\left(2 a_{1}\right) ; f_{3}=\left(x-b_{1}\right) / b_{1} ; \\
& f_{4}=\left(a_{2}+y\right)\left(a_{2}-y\right) /\left(2 a_{2}\right) ; f_{5}=\left(r^{2}-\left(x-b_{1}\right)^{2}-(y-c)^{2}\right) /(2 r) ; \\
& f_{6}=\left(r^{2}-\left(x-b_{1}\right)^{2}-(y+c)^{2}\right) /(2 r) ;
\end{aligned}
$$

$a_{1}$ is one-half width at atomiser inlet; $a_{2}$ is one-half width at atomiser outlet; $b_{1}+b_{2}$ is atomiser length; $b_{1}$ is a value, by which the circle centre is displaced from the inlet on axis $\mathrm{Ox} ; c$ is a value, by which the circle centre is displaced from the inlet axis of symmetry on axis $\mathrm{Oy} ; r$ is circle radius.

For functions $\psi_{1}$ and $\psi_{0}$, equation (4) has the form:

$$
\begin{aligned}
& \frac{1}{\operatorname{Re}} \Delta \Delta \psi_{1}-\left\{\frac{\partial \psi_{1}}{\partial y} \cdot \frac{\partial \Delta \psi_{1}}{\partial x}-\frac{\partial \psi_{1}}{\partial x} \cdot \frac{\partial \Delta \psi_{1}}{\partial y}\right\}-\frac{\partial \psi_{1}}{\partial y} \cdot \frac{\partial \Delta \psi_{0}}{\partial x}-\frac{\partial \psi_{0}}{\partial y} \cdot \frac{\partial \Delta \psi_{1}}{\partial x}+ \\
& +\frac{\partial \psi_{1}}{\partial x} \cdot \frac{\partial \Delta \psi_{0}}{\partial y}+\frac{\partial \psi_{0}}{\partial x} \cdot \frac{\partial \Delta \psi_{1}}{\partial y}=-\frac{1}{\operatorname{Re}} \Delta \Delta \psi_{0}+\frac{\partial \psi_{0}}{\partial y} \cdot \frac{\partial \Delta \psi_{0}}{\partial x}-\frac{\partial \psi_{0}}{\partial x} \cdot \frac{\partial \Delta \psi_{0}}{\partial y} .
\end{aligned}
$$

Linearisation yields a sequence of linear equations [11]:

$$
\begin{aligned}
& \frac{1}{\operatorname{Re}} \Delta \Delta \psi_{n+1}-\left\{\frac{\partial \psi_{n}}{\partial y} \cdot \frac{\partial \Delta \psi_{n+1}}{\partial x}+\frac{\partial \psi_{n+1}}{\partial y} \cdot \frac{\partial \Delta \psi_{n}}{\partial x}-\frac{\partial \psi_{n}}{\partial x} \cdot \frac{\partial \Delta \psi_{n+1}}{\partial y}-\frac{\partial \psi_{n+1}}{\partial x} \cdot \frac{\partial \Delta \psi_{n}}{\partial y}\right\}- \\
& -\frac{\partial \psi_{n+1}}{\partial y} \cdot \frac{\partial \Delta \psi_{0}}{\partial x}-\frac{\partial \psi_{0}}{\partial y} \cdot \frac{\partial \Delta \psi_{n+1}}{\partial x}+\frac{\partial \psi_{n+1}}{\partial x} \cdot \frac{\partial \Delta \psi_{0}}{\partial y}+\frac{\partial \psi_{0}}{\partial x} \cdot \frac{\partial \Delta \psi_{n+1}}{\partial y}=-\frac{1}{\operatorname{Re}} \Delta \Delta \psi_{0}+ \\
& +\frac{\partial \psi_{0}}{\partial y} \cdot \frac{\partial \Delta \psi_{0}}{\partial x}-\frac{\partial \psi_{0}}{\partial x} \cdot \frac{\partial \Delta \psi_{0}}{\partial y}-\frac{\partial \psi_{n}}{\partial y} \cdot \frac{\partial \Delta \psi_{n}}{\partial x}+\frac{\partial \psi_{n}}{\partial x} \cdot \frac{\partial \Delta \psi_{n}}{\partial y} .
\end{aligned}
$$

The least-squares method is used to solve the problem [20]. The static pressure is found from the Poisson equation with a right-hand side depending on the found stream function $[13,14]$. The approximate solution is understood to be in the sense of norm $L_{2}(\Omega)$.

Equation (6) is solved for function $P$ in domain $\Omega$.

Let us consider the statement of boundary conditions for equation (6): on the solid wall 
$\left(\Gamma_{1}\right.$ and $\left.\Gamma_{2}\right), \frac{\partial P}{\partial n}=0$; at the passage inlet $\left(\Gamma_{4}\right), \frac{\partial P}{\partial n}=$ const ; at the passage outlet $\left(\Gamma_{5}\right)$, $P=$ const .

The structure of solution of the boundary-value problem for equation (6) with respective boundary conditions has the form:

$$
\begin{aligned}
& P=P_{2} \omega_{2}-\omega\left(\frac{\partial \omega_{1}}{\partial x} \frac{\partial\left(P_{2} \omega_{2}\right)}{\partial x}+\frac{\partial \omega_{1}}{\partial y} \frac{\partial\left(P_{2} \omega_{2}\right)}{\partial y}\right)-\omega \varphi+\omega_{1}^{2} \omega_{2} P_{3}+C, \text { where: } \\
& \omega_{1}=\left(f_{1} \wedge_{0} f_{2}\right) \vee_{0}\left(f_{3} \wedge_{0} f_{4}\right) \vee_{0}\left(f_{5} \vee_{0} f_{6}\right) ; \\
& \omega=\left(f_{1} \wedge_{0} f_{2}\right) \vee_{0}\left(f_{7} \wedge_{0} f_{4}\right) \vee_{0}\left(f_{5} \vee_{0} f_{6}\right) ; \\
& \omega_{2}=\left(b_{1}+b_{2}-x\right) ; f_{7}=\left(x-b_{1}\right)\left(b_{1}+b_{2}-x\right) / b_{2} ; \\
& P_{2}=\sum_{i=1}^{N} C_{i} \zeta_{i} ; P_{3}=\sum_{i=1}^{N} D_{i} \zeta_{i} ; \\
& C_{i}, D_{i} \text { are constants to be found. }
\end{aligned}
$$

$C$ is static pressure value at the passage outlet (the constant is specified based on the problem physical statement; in our case, $C=1$ );

$\varphi=\sum_{i=1}^{3} \frac{\varphi_{i}}{w_{i}} / \sum_{i=1}^{3} \frac{1}{w_{i}}$ is a function whose values on the sections of the domain

boundary coincide with the derivative for the normal of function $P$ on respective sections of the boundary, on which the Neumann condition has been specified. This function is built using the patching formula [10].

Here, $\varphi_{i}$ are Neumann conditions specified on the boundaries of $\Gamma_{i}$ :

$$
\varphi_{i}=0, i=1,2 ; \varphi_{3}=\frac{8}{E u \operatorname{Re} a^{2}} \text {. }
$$

\subsection{Results of Computational and Experimental Research}

Figs. 3-5 show the results of computational experiments: distributions of velocities and pressures in domain $\Omega$. The computational experiments were run on a $40 \times 40$ mesh of $5^{\text {th }}$-order splines. The number of iterations was nine.

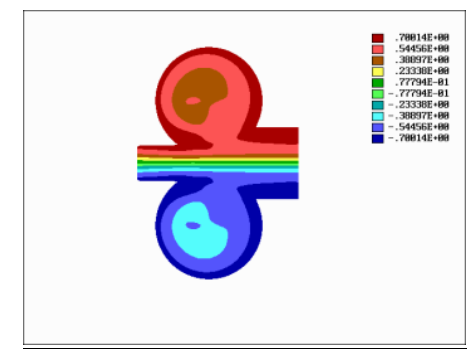

Fig. 3. Stream function $(\mathrm{R} e=1,000)$.

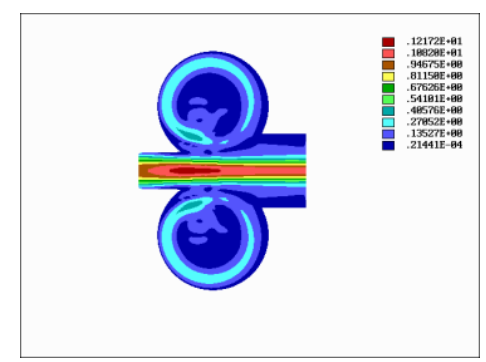

Fig. 4. Velocity module function $(\mathrm{R} e=1,000)$. 


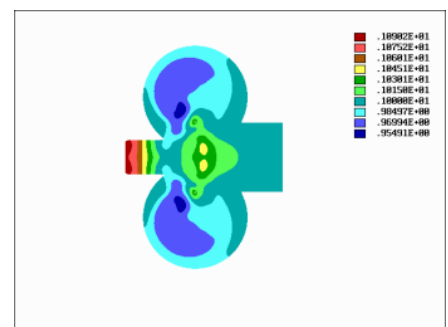

Fig. 5. Static pressure function $(\mathrm{R} e=1,000, E u=10)$.

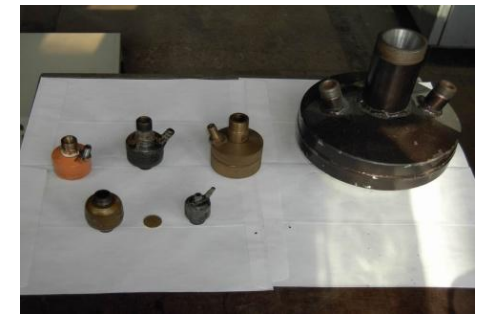

Fig. 6. Types of mixer atomisers

The solution of the fluid dynamics problem in the axisymmetric domain enabled developing actual devices for ultrafine atomisation - hydrovortex atomisers [6-9]. The unique feature of these atomisers is their capability to ensure high-quality atomisation in the combustion chambers of heat generating installations of ACLF suspensions and emulsions with different physical-chemical properties, including those with a different content of the dispersion $k$-phase. Numerical and full-scale experiments have shown that the atomiser ensures conditions for initiation of cavitation. In emulsions of the "water-hydrocarbon" kind, it evokes partial hydrogenation of high-molecular fractions.

Theoretical, numerical and experimental research served as an underpinning for developing hydrovortex atomisers for different practical applications (Fig. 6).

\section{Industrial Pilot Tests}

As an illustration of implementation of the developed methodology of design and development of atomisers, we offer the most complex case - atomiser application for developing an installation for combustion of ACLF, comprising bio sludge of waste treatment plants (humidity about $85 \%$ ), water and a hydrocarbon fraction. The challenge is that ACLF is a viscous emulsion with inclusion of a solid sediment. Managing the atomisation and steady combustion of such fuel is a complicated process. No known designs of atomisers have given a stable result. Poor atomisation quality, rapid nozzle orifice clogging, and the need to maintain high flow pressure at the atomiser inlet are just some of the challenges of using centrifugal, pneumatic and other kinds of standard atomisers.

Flame tests of atomisers developed for atomising alternative fuel were conducted at waste treatment plants in Kharkiv as part of an installation for ACLF production and combustion, which was developed at the Kharkiv National Radio Electronics University, Fig. 7.

Research has shown that ultrafine ACLF droplets (size 5-15 $\mu \mathrm{m}$ ) are dispersed additionally in the high-temperature combustion zone due to rapid development of the emulsion phase, i.e. water inside the emulsion droplets transforms to steam, expands and sputters the hydrocarbon components. Oxidiser access to the fuel is improved, the processes of gasification in the solid filler are accelerated, and mechanical and chemical underburning is reduced. Visually, the flame resembles oxygen-hydrogen hightemperature combustion. The combustion flame increases in volume by $11-12 \%$ and fills the combustion chamber more densely. Heat transfer processes run smoother, and the 
efficiency of combustion of off-spec hydrocarbon fuel - spent oil in our case - reaches $99.5 \%$.

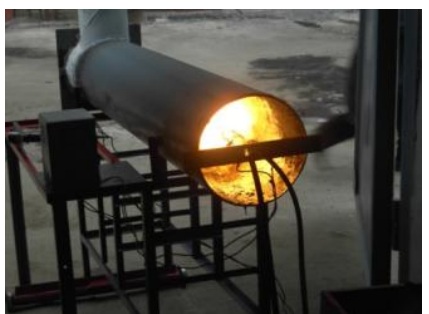

Fig. 7. Experimental set-up for fuel combustion

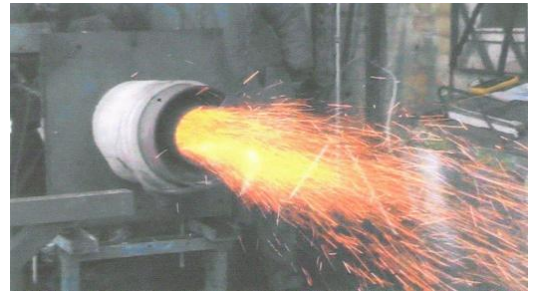

Fig. 8. Testing an atomiser burner for water-coal fuel

The developed atomiser prototype for combustion of alternative biofuel was tested with success and proved the advantages of the hydrocavitation approach to intensifying physico-chemical processes in atomising devices.

The described methodology was used to develop a hydrovortex atomiser for combustion of water-coal fuel. It was tested with success on the test bench at KP Kommunekoresursy in Donetsk (Fig. 8), having thereby confirmed the prospect of converting gas-and-oil-fired boilers to utilising coal slurries and ACLF as fuel.

The method of pre-combustion production and preparation of phenol sewage-based water-coal fuel, which is based on the hydrocavitation activation method, enables achieving utmost effectiveness of decontamination of waste effluents during composite fuel combustion [21-23].

The mock-up test sample of the atomiser passed the tests for combustion of alternative biofuel and confirmed the advantages of the hydrocavitation approach to intensifying physico-chemical processes in atomising devices.

The developed hydrocavitation technology for activation of hydrocarbon-containing emulsions and suspensions was tested at several power facilities in Ukraine and Poland where it demonstrated extraordinary energy-ecological effectiveness [24-30].

For instance, the NPP Prom-TEK enterprise (town of Merefa), introduced technologies and hydrocavitation activation equipment - installations for producing high-quality diesel-oil emulsions, distillation fractions from oil refining stillage bottoms and process sluicing of oil products, ultrafine atomisation and combustion of off-spec fuels.

Fig. 9 shows the tests of a working sample of a hydrovortex atomiser in an operating boiler. The tests were conducted with diesel-oil fuel. Note that this sample yielded the best energy and ecological boiler performance indicators as compared with that of atomisers of other types in the market.
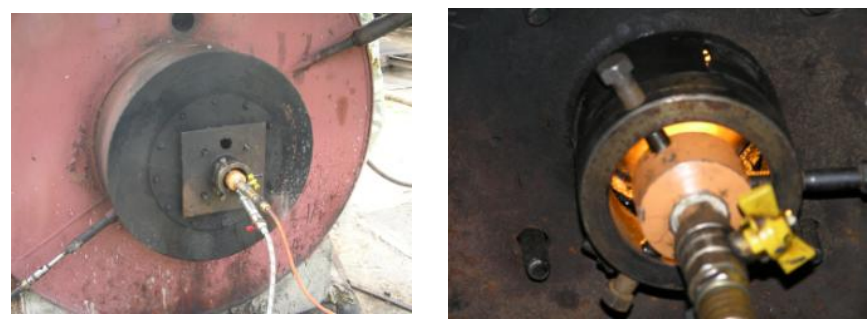

Fig. 9. Testing a bydrovortex atomiser at a mini oil refinery. 
LLC Monastyrishchenskaya Production and Research Adaptation Firm ENERGETIK conducted successful pilot tests on steam boiler E-1.0-0.9G-S (E) of combustion of fuel oil-based composite fuel with addition of waste from municipal waste treatment plants. The tests used the developed burner built around the hydrocavitation atomiser.

During the tests, the thermal physical characteristics of the composite fuel were determined against those of source hydrocarbon by measuring fuel mass consumption per 1 ton of boiler steam capacity. The results of heat engineering investigations are given in Table 1.

Table 1: Results of heat engineering investigations in combustion of composite fuel

\begin{tabular}{|l|c|c|c|c|}
\hline Fuel & $\begin{array}{c}\text { Gas temperature, } \\
{ }^{\circ} \mathrm{C}\end{array}$ & $\begin{array}{c}\text { Steam pressure, } \\
\mathrm{MPa}\end{array}$ & $\begin{array}{c}\text { Boiler } \\
\text { efficiency, } \%\end{array}$ & $\begin{array}{c}\text { Fuel consumption } \\
\text { per ton of steam, kg }\end{array}$ \\
\hline Stillage bottoms & 302.4 & 0.4 & 81.8 & 92 \\
\hline CF $(30 \%$ bio sludge $)$ & 293.2 & 0.4 & 83.2 & 116 \\
\hline CF $(35 \%$ bio sludge $)$ & 291.8 & 0.4 & 84.6 & 120 \\
\hline CF $(40 \%$ bio sludge $)$ & 291.4 & 0.4 & 87.7 & 132 \\
\hline CF $(45 \%$ bio sludge $)$ & 289.5 & 0.4 & 85.8 & 144 \\
\hline CF $(50 \%$ bio sludge $)$ & 286.6 & 0.4 & 86.0 & 157 \\
\hline
\end{tabular}

As the Table shows, the consumption of composite fuel with addition of $50 \%$ of bio sludge to generate one ton of steam as compared to that of the source hydrocarbon, increased only by $30 \%$. This is due to the change in the structure and chemical composition of the fuel mix during hydrocavitation activation. During the process, solid particles are subject to cavitation comminution and activation with the emergence of a big amount of free organic radicals, cleavage of long hydrocarbon chains and, as a consequence, the formation of new fuel molecules. Hence, hydrocavitation activation, due to enabling the flow of sonochemical reactions between fuel components, facilitates the growth of light fractions and formation of new hydrocarbon molecules interacting with active organic substances and the bio sludge of waste treatment plants.

Extraction of nonconventional hydrocarbons per one hydrofracing ( $\mathrm{HF}$ ) series requires the average consumption of $10,000 \mathrm{~m}^{3}$ of water, followed by formation of $5,000 \mathrm{~m}^{3}$ of heavily contaminated spent liquid remaining in place after the HF operations have been completed. This is the foremost ecological challenge in regions where nonconventional hydrocarbons are extracted.

Investigations into the composition of hydrofracing waste effluents have shown that hazardous contaminants contained in this spent liquid are boron compounds and organic amines formed by decomposition of component parts.

The technology based on the methodology of hydrocavitation activation enables reclaiming the hydrofracing spent liquid during production of nonconventional gases. A technology has been developed for all-round reclamation of hydrofracing spent liquid as a component of composite fuel.

Applying hydrocavitation activation methods has been found to enable the production of high-quality composite boiler fuels. The proposed technological approach can be used for reclamation and deactivation of organo-mineral effluents of various origin [31, 32].

Table 2 summarises the results of analysing flue gases during combustion of diesel fuel 
(DF)-based composite fuel with addition, as an aqueous phase (AP), of preliminarily concentrated hydrofracing spent liquid.

Table 2: Results of analysing flue gases

\begin{tabular}{|l|c|c|c|c|c|c|c|c|}
\hline Investigated fuel & $\begin{array}{c}\mathbf{O}_{2}, \\
\mathbf{9}\end{array}$ & $\begin{array}{c}\mathbf{C O}, \\
\mathbf{m g} / \mathbf{m}^{\mathbf{3}}\end{array}$ & $\begin{array}{c}\mathbf{N O}, \\
\mathbf{m g} / \mathbf{m}^{\mathbf{3}}\end{array}$ & $\begin{array}{c}\mathbf{S O}_{2}, \\
\mathbf{m g} / \mathbf{m}^{\mathbf{3}}\end{array}$ & $\begin{array}{c}\mathbf{C O}_{2}, \\
\mathbf{\%}\end{array}$ & $\begin{array}{c}\text { Air excess } \\
\text { factor }\end{array}$ & $\begin{array}{c}\mathbf{~ N O x ,} \\
\mathbf{m g} / \mathbf{m}^{\mathbf{3}}\end{array}$ & $\begin{array}{c}\mathbf{T}, \\
{ }^{\circ} \mathbf{C}\end{array}$ \\
\hline $\begin{array}{l}80 \% \text { DF + 20\% AP } \\
\text { (HF spent liquid) }\end{array}$ & 5.1 & 45 & 103 & 68 & 12.2 & 1.21 & 160 & 883.5 \\
\hline $\begin{array}{l}80 \% \text { DF + 20 \% AP } \\
\text { (double concentrate) }\end{array}$ & 4.2 & 70 & 109 & 76 & 12.1 & 1.27 & 168 & 903.5 \\
\hline $\begin{array}{l}80 \% \text { DF + 20 \% AP } \\
\text { (10-fold concentrate) }\end{array}$ & 4.1 & 55 & 112 & 85 & 11.9 & 1.24 & 171 & 887.0 \\
\hline $\begin{array}{l}80 \% \text { DF + 20 \% AP } \\
\text { (20-fold concentrate) }\end{array}$ & 4.4 & 60 & 116 & 100 & 12.4 & 1.26 & 177 & 898.6 \\
\hline MAC norm & - & 250 & - & 500 & - & - & 500 & - \\
\hline
\end{tabular}

Analysis of combustion products during combustion of the composite fuel being investigated (Table 2) has shown that, as to its properties, it complies with effective ecological standards and requirements to the fuel used in power boiler units. Analysis for presence of organic amines in the combustion products has demonstrated their complete flame deactivation in all samples of the composite fuel being investigated.

Investigations have confirmed complete deactivation of organic amines with water volume saving of about $5,000 \mathrm{~m}^{3}$ (for one hydrofracing), prevention of ingress into surface water bodies of the average of 180 tons of mineral salts, and of the average of 10 tons of toxic organic substances into surface reservoirs and the atmosphere.

\section{Conclusions}

Methods have been developed and proposed for intensifying the processes of preparation of emulsion and suspension fuels and their ultrafine atomising by employing cavitation phenomena. Mathematical modelling and computer simulation of flow in a hydrovortex atomiser has been performed.

Results of experimental research in the developed hydrovortex atomisers as part of an installation for production and combustion of artificial composite liquid fuels are presented.

The tests have demonstrated the advantages of employing the proposed principles for preliminary activation of fuels, and have proved that the usage of hydrocavitation technologies of preparing and atomising fuels can dramatically improve the economic performance and ecological indices of the effectiveness of operation of power installations. Thus, combustion of composite fuel with addition of hydrofracing spent liquid enables complete flame deactivation of organic amines. Combustion of composite fuel, with addition of active sludge from waste treatment plants, provides not only flame reclamation of waste, but also the generation of surplus heat energy by formation of new fuel molecules during hydrocavitation activation at the stages of preparation and combustion of a fuel composition. 


\section{References}

Kravchenko O.V. Nonconventional energy technologies for effective production and usage of artificial composite liquid fuels / O.V. Kravchenko, I.G. Suvorova, Ya.V. Smirnov, S.S. Kholobtsev // Aerospace Engineering and Technology. - 2006. Issue.- No. 10(36). - pp. 91-97.

Kravchenko O.V. Nonconventional methods for production and combustion of liquid fuels / O.V. Kravchenko, I.G. Suvorova, S.S. Kholobtsev // Bull. Int. Slovianskyi University. - 2007. - v. 10. - No. 1. - pp. 14-19.

Kravchenko O.V. Nonconventional methods for producing artificial composite liquid fuels / O.V. Kravchenko, I.G. Suvorova, S.S. Kholobtsev // Bull. SevGTU. Ser. Mekhanika, energetika, ekologia [Mechanics, energy production, ecology]. - Sevastopol: SevNTU, 2008. - Issue 87. - pp. 34-38.

Kravchenko O.V. New hydrocavitation technologies in processes of effective production and usage of hydrocarbon-containing energy carriers / O.V. Kravchenko // Bull. National Technical University "Kharkiv Polytechnic Institute". - Kharkiv: NTU "KhPI", 2007. - No. 2. - pp. 171178.

Kravchenko O.V. Physico-chemical conversions of hydrocarbon compounds by using new cavitation devices / O.V. Kravchenko // Aerospace Engineering and Technology. - 2007. - Issue 1(37). pp. 65-69.

Patent No. 2083247 RF, IPC 3 A62C 31/02. Device for atomising a liquid / Glotov Ye.A., Suvorova I.G. Kharkiv State Technical University for Building and Architecture (Ukraine). - No. 94003528/12; filed 01.02.1994; publ. 10.07.1997, Bull. No. 19 // Discoveries, Inventions, Designs, Trademarks.- 1997. - No. 19. - p. 27.

Patent 81479, Ukraine, IPC (2006) B01F 7/00, C10G 7/06. Method for processing fuel oil and a rotorcavitation disperser therefor / I.I. Miroshnichenko, I.G. Suvorova, Yu.M. Matsevity, O.V. Kravchenko, A.A. Tarelin; Applicant and Patentee O.M. Pidhirnyi Inst. for Mechanical engineering Problems NAS Ukraine. - No. a 2005 10753; filed 14.11.2005; publ. 10.01.08, Bull. No. 1.

Patent 82138, Ukraine, IPC (2006) B01F 5/02, B01F 5/04, B01F 5/06, B02C 19/06. Mixing nozzle / I.G. Suvorova, O.V. Kravchenko; Applicant and Patentee O.M. Pidhirnyi Inst. for Mechanical Engineering Problems NAS Ukraine. - No. a 2006 06859; filed 19.06.2006; publ. 11.03.08, Bull. No. 5.

Utility patent 89291 Ukraine, IPC (2014.01) F23D 11/00, B01F 3/00, B01F 5/00. Activator atomiser / Kravchenko O.V., Suvorova I.G., Baranov I.A., Tarasenko L.V.; Applicant and Patentee O.M. Pidhirnyi Inst. for Mechanical Engineering Problems NAS Ukraine. - No. u 2013 14346; filed 09.12.2013; publ. 10.04.2014, Bull. No. 7.

Rvachev V.L. Theory of R-functions and its applications / V.L. Rvachev. - Kyiv: Nauk. Dumka, 1982. $552 \mathrm{p}$.

Suvorova I.G. Computer simulation of axisymmetric liquid flow in intricate passages // Bull. Nat. Techn. Univ. "KhPI". - 2004. - No. 31. - pp. 141-48.

Suvorova I.G., Kravchenko O.V. Mathematical modelling of a liquid flow using the R-functions method // System Technologies. - 2006. - Issue 4 (45). - pp. 57-69.

Baranov I.A. The R-functions method for analysis of interrelated fields in fluid flows / I.A. Baranov, O.V. Kravchenko, I.G. Suvorova // Bull. Kharkiv National University. Series Mathematical modelling. Information technologies. Automated control systems - Kharkiv: KhNU, 2007. - No. 780. - pp. 9-18.

Baranov I.A. Analysis of the fluid dynamics of a flow of viscous incompressible liquid with the R-functions method / I.A. Baranov, O.V. Kravchenko, I.G. Suvorova // Bull. Kharkiv National University. Series Mathematical modelling. Information technologies. Automated control systems- Kharkiv: KhNU, 2008. - No. 809. - pp. 9-19.

Kravchenko O.V. Improving processes and apparatuses for hydrocavitation activation by using mathematical modelling and computer simulation / O.V. Kravchenko, I.G. Suvorova, I.A. Baranov // Proc. Modelling and Information Technologies. - Kyiv: G.Ye. Pukhov Inst. for Modelling in Power Engineering NAS Ukraine, 2010. - v. 3. - pp. 186-194.

Suvorova I.G. Mathematical modelling of fluid flow by using the R-functions method / I.G. Suvorova, O.V. Kravchenko // System Technologies.- Dnipropetrovsk: DNVP System Technologies, 2006. - Issue 4 (45). - pp. 57-69. 
Suvorova I.G. Mathematical and computer modelling of axisymmetric flows of an incompressible viscous fluid by the method of R-functions / I.G. Suvorova, O.V. Kravchenko, I. A. Baranov // Journal of Mathematical Sciences. Springer US, 2012. - Vol. 184. - No. 2. - pp. 165-180.

Iryna Suvorova. Investigating the hydrodynamics of flows in channels of complex geometric forms. International Conference Differential Equations, Mathematical Physics and Applications, October 17 - 19, 2017, Cherkasy, Ukraine. Book of Abstracts. - Vinnytsia: Vasyl' Stus Donetsk National University, 2017. - pp. 84-85.

Landau L.D., Lifshitz Ye.M. Theoretical Physics: v.6. Fluid Mechanics. - Moscow: Nauka, 1988. - 736 p.

Mikhlin S.G. Variational Methods in Mathematical Physics / S.G. Mikhlin. - M.: Nauka, 1970. - 512 p.

Andrienko Ye.Yu. Method for flame dephenolisation of sewage from coking plants. / Ye.Yu. Andrienko, A.V. Basteev, O.V. Kravchenko, L.V. Tarasenko, P.V. Karnozhytskii, K. Yusef // Uglekhimicheskii Zhurnal [Coke and By-product Journal]. - 2009. - No. 5-6. - pp. 72-77.

Andrienko Ye.Yu. Energy and ecological aspects of using phenol sewage as a component of composite fuels / Ye.Yu. Andrienko, O.V. Kravchenko, I.G. Suvorova // Modern science: research, ideas, results, technologies. - Kyiv: NPVK Triakon, 2012. - No. 1(9). - pp. 31-35.

Kravchenko O.V. Energy and environmental aspects of using phenol wastes as a component of hydrocarbon fuels / O.V. Kravchenko, Ye.Yu. Andrienko // Ecology and Industry. -2011. - N3. - p. 67-71.

Kravchenko O.V. Activation of preflame processes in suspension fuels based on fuel oil and fine coal dust / O.V. Kravchenko, A.V. Basteev, L.V. Tarasenko // Eco Technologies and Resources Conservation. - 2008. - No. 2. - pp. 4-7.

Kravchenko O.V. Improving the quality of atomisation of process fluids in power installations / O.V. Kravchenko, I.G. Suvorova, I.A. Baranov // East-European Journal of Advanced Technologies. - 2009. - 4/6(40). - pp. 34-38.

Kravchenko O.V. Complex for conducting investigations in the processes of production, preparation and combustion of new kinds of composite fuels / O.V. Kravchenko, I.G. Suvorova, V.A. Goman, Ye.Yu. Musienko, A.M. Danilenko // Tekhnicheskaya Teplofirika i Promyshlennaya Teploenergetika [Engineering Heat Physics and Industrial Thermal Power Engineering. - Dnipro: Lira Ltd, 2013. - No. 5. - pp. 150-160.

Kravchenko O.V. Hydrocavitation activation in technologies of production and combustion of composite fuels and an appraisal of its efficiency / O.V. Kravchenko, I.G. Suvorova, I.A. Baranov // Nasosy. Turbiny. Sistemy [Pumps. Turbines. Systems] - 2014. - No. 4(13). - pp. 57- 65.

Kravchenko O.V. Promising technologies of production and combustion of composite fuels based on activation methods / O.V. Kravchenko, I.G. Suvorova, I.A. Baranov, V.A. Goman // Municipal Utilities. Series: Energy-effective equipment and technologies in municipal utilities. - Kharkiv: O.M. Beketov Kharkiv National University, 2014. - Issue 118(1). - pp. 29-33.

Harold N. Knickle, Oleg Kravchenko, Igor Baranov, Iryna Suvorova. Non-Conventional Methods of Obtaining Combustible Liquid Fuels. 2015 Spring Meeting \& 11th Global Congress on Process Safety (56 ${ }^{\mathrm{d}}, 7 \mathrm{p}$.). (ISBN: 978-0-8169-1089-2).

O. Kravchenko, I. Suvorova, I. Baranov, V. Goman. Hydrocavitation activation in the technologies of production and combustion of composite fuels. Eastern-European Journal of Enterprise Technologies, 2017, 4 /5 (88), P. 33 - 42.

Kravchenko O.V. No-effluent technology of recovering spent HF fluid / O.V. Kravchenko, A.O. Tarelin, V.G. Mikhailenko, I.A. Baranov // International Geological Forum "Topical issues and prospects of development of geology: research and production" (GEOFORUM-2015). Forum materials (Ukraine, Odesa, 7-12 Sept. 2015. In two volumes. V. 2. Ukrainian State Geological Survey Institute (Ukr. DGRI). K.: UkrDGRI, 2015. - pp. 108-115.

Utility patent 105507 Ukraine, IPC (2015.01) C02F 1/00, C02F 1/44 (2006.01), C02F 9/00. Method for zero-discharge reclamation of effluents contaminated with mineral and organic substances / Tarelin A.O., Kravchenko O.V., Mykhailenko V.H., Suvorova I.G., Baranov I.A., Tarelin A.A., Antonov O.V., Kniazeva O.I.; Applicant and patentee Research and Engineering Concern Institute for Mechanical Engineering Problems NAS Ukraine. - No. u 2015 08447; filed 28.08.2015; publ. 25.03.2016, Bull. No. 6. 